\title{
THE
}

\section{Evidence of Bottom-Trapped Currents in the Kuroshio Extension Region}

Stuart P. Bishop

University of Rhode Island

D. Randolph Watts

University of Rhode Island, randywatts@uri.edu

Jae-Hun Park

Nelson G. Hogg

Follow this and additional works at: https://digitalcommons.uri.edu/gsofacpubs

Terms of Use

All rights reserved under copyright.

\section{Citation/Publisher Attribution}

Bishop, S. P., Watts, D. R., Park, J.-H., \& Hogg, N. G. (2012). Evidence of Bottom-Trapped Currents in the Kuroshio Extension Region. Journal of Physical Oceanography, 42, 321-328. doi: 10.1175/JPO-

D-11-0144.1

Available at: http://dx.doi.org/10.1175/JPO-D-11-0144.1

This Article is brought to you for free and open access by the Graduate School of Oceanography at DigitalCommons@URI. It has been accepted for inclusion in Graduate School of Oceanography Faculty Publications by an authorized administrator of DigitalCommons@URI. For more information, please contact digitalcommons-group@uri.edu. 


\title{
Evidence of Bottom-Trapped Currents in the Kuroshio Extension Region
}

\author{
STUART P. BISHOP AND D. RANDOLPH WATTS \\ Graduate School of Oceanography, University of Rhode Island, Narragansett, Rhode Island \\ JAE-HUN PARK \\ Korea Ocean Research and Development Institute, Ansan, South Korea \\ NeLson G. HoGG \\ Cornell University, Ithaca, New York
}

(Manuscript received 18 August 2011, in final form 22 October 2011)

\begin{abstract}
As part of the Kuroshio Extension System Study, observations from five current meter moorings reveal that the abyssal currents are weakly bottom intensified. In the framework of linear quasigeostrophic flow, the best fitted vertical trapping depths range from 8 to $15 \mathrm{~km}$ in the absence of steep topography, but one mooring near an isolated seamount exhibited vertical trapping that was more pronounced and energetic with a vertical trapping depth of $5 \mathrm{~km}$. The ratios of current speeds and geostrophic pressure streamfunctions at the sea surface compared to the bottom are $88 \%$ in the absence of steep topography, $63 \%$ near an isolated seamount, and overall on average $83 \%$ of their value at a reference depth of $5300 \mathrm{~m}$. It is hypothesized that weakly depth-dependent eddies impinging upon topographic features introduce to the flow the horizontal length scales of the topography, and these smaller lateral scales are subject to bottom intensification.
\end{abstract}

\section{Introduction}

To first order ocean bathymetry plays a crucial role in large-scale ocean circulation given that low-frequency flow is constrained to follow $f / h$ contours, where $f$ is the Coriolis parameter and $h$ is the fluid depth. Locally, when interacting with topography, subinertial flow has been observed to take on complex motion, including amplification of currents near seamounts (Lavelle and Mohn 2011).

From linear quasigeostrophic (QG) flow in a continuously stratified fluid, bottom intensification of currents arises from two modes of variability: topographic Rossby waves (TRWs; Rhines 1970) and a vertically decaying wave solution for mean flow over a wavy bottom (Gill 1982). The wave solutions for the horizontal currents take the vertical structure of $\cosh (z / b)$ by imposing a top rigid-lid boundary condition, where $z$ is the vertical

Corresponding author address: Stuart P. Bishop, Graduate School of Oceanography, University of Rhode Island, 215 South Ferry Rd., Narragansett, RI 02882.

E-mail: sbishop@gso.uri.edu coordinate in a Cartesian coordinate system with origin at the sea surface. The vertical trapping scale is $b=(f / N) K^{-1}$ and is sometimes referred to as the Rossby height (Gill 1982), where $N$ is the buoyancy frequency and $K=\sqrt{\left(k^{2}+l^{2}\right)}$ is the horizontal wavenumber.

More generally in geophysical fluid dynamics problems where rotation and stratification are of comparable importance, the Burger number $(\mathrm{Bu})$ is $O(1)$ where $\mathrm{Bu}=N b / f L$; here $b$ is a characteristic depth scale and $L$ is the horizontal length scale of the flow. When the depth scale is the ocean depth $(b=h)$ the horizontal length scale of the flow is the internal deformation radius $\left(L_{D}\right)$. There are other cases that may arise in which the horizontal length scale of the flow is set either by the prevalent eddy scale $\left(L_{E}=2 \pi / K_{E}\right.$, where $K_{E}$ is the eddy wavenumber) or by local topographic features $\left(L_{T}=\delta h / \alpha\right.$, where $\delta h$ is the change in fluid depth over a horizontal distance and $\alpha=|\nabla h|$ is the topographic slope). The vertical scale may then be estimated from $b=(f / N) L$.

Since TRWs are expected to be present over topographic slopes, many observational studies have focused their efforts on these regions. A series of observational 
comparisons with TRW theory have taken place using current meters in the Gulf Stream region testing for bottom trapping (Thompson and Luyten 1976; Hogg 1981; Johns and Watts 1986; Hogg 2000). Johns and Watts (1986) estimated $b^{-1}=0.33 \mathrm{~km}^{-1}(b=3030 \mathrm{~m})$ in a region of modest topographic slope $(\alpha \approx 0.01)$. In a steeper environment $(\alpha \approx 0.01-0.03)$, Hogg (2000) found evidence for bottom trapping associated with TRWs from current meter moorings deployed on the western flanks of the Grand Banks. There is also evidence of bottom trapping associated with TRWs in the Gulf of Mexico (Hamilton 1990, 2007). Hamilton (2007) observed $\sim 10$-day period TRWs along the Sigsbee Escarpment. These waves were strongly bottom trapped and traced to within $300 \mathrm{~m}$ of the surface. Similar to Thompson and Luyten (1976) and Hogg (2000), Hamilton (2007) estimated vertical trapping scales $(683-1588 \mathrm{~m})$ associated with the TRWs and their corresponding wavelengths $(65-151 \mathrm{~km})$ from multiple current meters on a single current meter mooring.

The Kuroshio Extension System Study (KESS) was a multi-institutional field study to identify and quantify the processes governing the variability of and the interaction between the Kuroshio Extension and its recirculation gyres (Donohue et al. 2008). The KESS field program comprised a roughly $600 \mathrm{~km} \times 600 \mathrm{~km}$ array of 46 current and pressure equipped inverted echo sounders (CPIES) (Donohue et al. 2010) and 7 subsurface moorings (Jayne et al. 2009) that were deployed for two years from 2004 to 2006. The KESS array sought even site spacing but shifted some sites to avoid seamounts and steep topography. The large-scale topographic slope was generally downward toward the south-southeast with $\alpha \sim 0.01$, and locally slopes were as large as $\alpha \sim 0.1$. Greene (2010) found from the array of CPIES deep current and pressure measurements prominent abyssal variability from eddies in the 3060 -day band. These eddies originated outside the KESS region; Greene suggested the origin to be the Shatsky Rise. Although nonlinear, their kinematics resemble TRWs, and the eddies propagate from northeast to southwest following the large-scale bathymetry.

Several studies have observed the large-scale deep circulation in the Kuroshio Extension region (Schmitz et al. 1982; Hallock and Teague 1996; Fujio and Yanagimoto 2005; Yanagimoto et al. 2010), but these do not address bottom trapping. In the framework of linear QG flow, the degree to which the large-scale deep currents and eddies are bottom trapped in the Kuroshio Extension region will be determined in this paper from the KESS line of current meter moorings, CPIES and satellite altimetry comparisons, and one additional mooring from the Kuroshio Extension Regional Experiment (KERE) (Fig. 1).

\section{Methods}

\section{a. Current meters}

Seven current meter moorings were deployed for two years east of Japan between the first quasi-stationary meander crest and trough of the Kuroshio Extension as part of KESS (Fig. 1). The moorings spanned the jet diagonally from north-northeast to south-southwest and were located along a Jason-1 altimeter line. They were equipped with an ADCP, McLane Moored Profiler, and current meters at several deep levels (Jayne et al. 2009). This study will focus on the bottom three RCM11 current meters $(2000,3500$, and $5000 \mathrm{~m})$ at the five moorings that provided records longer than 500 days.

A $10 \%$ correction was applied because the RCM11 had been reported to bias current measurements low (Hogg and Frye 2007). In addition, the currents were 72-h low-pass filtered using a fourth-order Butterworth filter to remove diurnal and semidiurnal tidal influences.

The currents were adjusted to remove the shear from the strong upper baroclinic currents in the Kuroshio Extension region, which extended weakly below subthermocline depths. The upper baroclinic field had been mapped twice daily from the CPIES array as presented in Donohue et al. (2010). The shear associated with the upper field was weak below $1500 \mathrm{~m}$, but the contributions were removed from the time series. The rms current adjustments were $1.68 \pm 0.31,0.20 \pm 0.03$, and 0.013 $\pm 0.002 \mathrm{~cm} \mathrm{~s}^{-1}$ respectively at 2000,3500 , and $5000 \mathrm{~m}$, averaged over the five sites.

\section{b. Ratio method}

The degree of bottom trapping was determined by calculating the fractional decrease in current speed $\left(V=\sqrt{u^{2}+v^{2}}\right)$ from the value at $5000 \mathrm{~m}$. This was done by fitting a line to the scatterplots of speed at $2000\left(V_{2000}\right)$ and $3500 \mathrm{~m}\left(V_{3500}\right)$ versus $5000 \mathrm{~m}\left(V_{5000}\right)$ (Figs. 3a-c). A type II least squares regression, which minimizes the normal deviates, fit a line to the major axis to find the slope ( $m_{i}, i=1$ and 2, where $m_{1}$ and $m_{2}$ are the slopes of the $V_{2000}$ vs $V_{5000}$ and $V_{3500}$ vs $V_{5000}$ scatterplots, respectively). The vertical structure of the current speed was fitted by nonlinear least squares to the form $V(x, y, z, t)=$ $V_{0}(x, y, t) \cosh (z / b)$ to determine the best vertical trapping scale $(b)$ to the data from the following equation,

$$
m_{i}-R_{i}=\epsilon_{i}
$$

where $m_{i}$ is the observed ratio (slope of the linear fit) and $R_{i}$ is the fitted ratio 


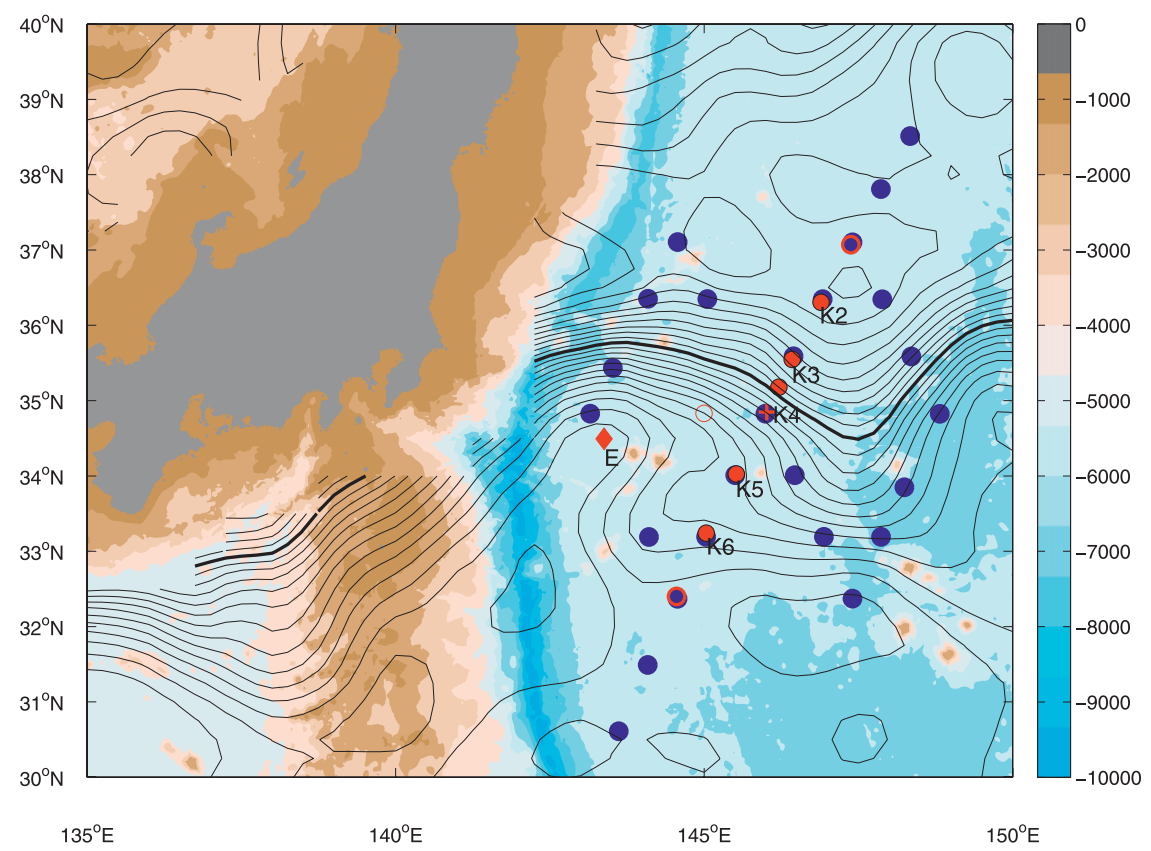

FIG. 1. KESS current meter mooring locations (red circles) superimposed over Smith and Sandwell topography (Smith and Sandwell 1997) [contour interval (CI) $=1000 \mathrm{~m}$ ] and mean SSH from Archiving, Validation, and Interpretation of Satellite Oceanographic data (AVISO) satellite altimetry product with Rio05 mean dynamic topography contours $(\mathrm{CI}=5 \mathrm{~cm})$ during June 2004-July 2006. The black bold contour is the 2.1-m contour, which is representative of the Kuroshio Extension axis. Blue circles represent the locations of 25 CPIES located along Jason-1 altimeter lines. The red cross marks the location of K4 during the second year of deployment. Open red circles indicate the locations of other KESS current meter moorings whose records were shorter than 500 days and were not used in this study. The red diamond indicates KERE mooring E.

$$
R_{i}=\frac{\cosh \left(z_{i} / b\right)}{\cosh \left(z_{3} / b\right)}
$$

where $z_{i}=-2000$ and $-3500 \mathrm{~m}, z_{3}=-5000 \mathrm{~m}$ is the deepest current meter, and $\epsilon_{i}$ is the difference between observed and fitted ratios, for which the sum of the squares is minimized. Error bars on $m_{i}$ were estimated by taking the standard error of the mean of $m_{i}$ calculated from three 6-month subsegments of the time series. Error bars on $b$ were then calculated using Eq. (1) from the bounds on $m_{i}$.

\section{c. EOFs}

Another method to determine the degree of bottom intensification was through the use of empirical orthogonal functions (EOFs). For comparison with the ratio method the first-mode EOF eigenvectors, $\lambda\left(z_{i}\right)$, were normalized by the value at $5000 \mathrm{~m}: \lambda_{n}\left(z_{i}\right)=$ $\lambda\left(z_{i}\right) / \lambda\left(z_{3}\right)$. Similar to the ratio method, a nonlinear least squares fit was used to determine $b$ by minimizing the pair of equations as in Eq. (1) but with the ratio $m\left(z_{i}\right)$ replaced by $\lambda_{n}\left(z_{i}\right)$. Error bars for $\lambda_{n}\left(z_{i}\right)$ and $b$ were calculated for three 6-month subsegments similarly to $m\left(z_{i}\right)$.

\section{d. $S S H$}

SSH anomalies $\left(\eta^{\prime}\right)$ derived from 25 CPIES collocated along Jason-1 altimeter lines (Fig. 1) were compared with SSH from satellite altimetry $\left(\eta_{\mathrm{alt}}^{\prime}\right)$ in research by J. Park (2011, personal communication). The CPIES SSH anomalies $\left(\eta_{\text {cpies }}^{\prime}\right)$ comprise a steric component $\left(\eta_{\mathrm{bc}}^{\prime}\right)$, derived from the CPIES acoustic travel time as proxy estimates of dynamic height (Watts et al. 2001; Park et al. 2005; Donohue et al. 2010), plus a mass loading component, $\eta_{\text {ref }}^{\prime}=p_{\text {bot }}^{\prime} / \rho_{\text {bot }} g$, where $p_{\text {bot }}^{\prime}$ is bottom pressure anomaly at $5300 \mathrm{~m}, \rho_{\text {bot }}$ is bottom density, and $g$ is gravity.

For comparison, the $\eta_{\text {alt }}^{\prime}$ and $\eta_{\text {cpies }}^{\prime}$ time series were fitted for a suite of values of $\gamma$, which scaled the mass loading term, $\eta_{\text {cpies }}^{\prime}=\eta_{\mathrm{bc}}^{\prime}+\gamma \eta_{\text {ref }}^{\prime}$. The best value of $\gamma$ was calculated two ways: by minimizing the rms difference or by maximizing the correlation. Horizontal currents and pressure have the same vertical structure, so $\gamma$ is related to the preceding vertical structure [Eq. (2)] as the ratio of perturbation pressure at the surface and sea floor: 

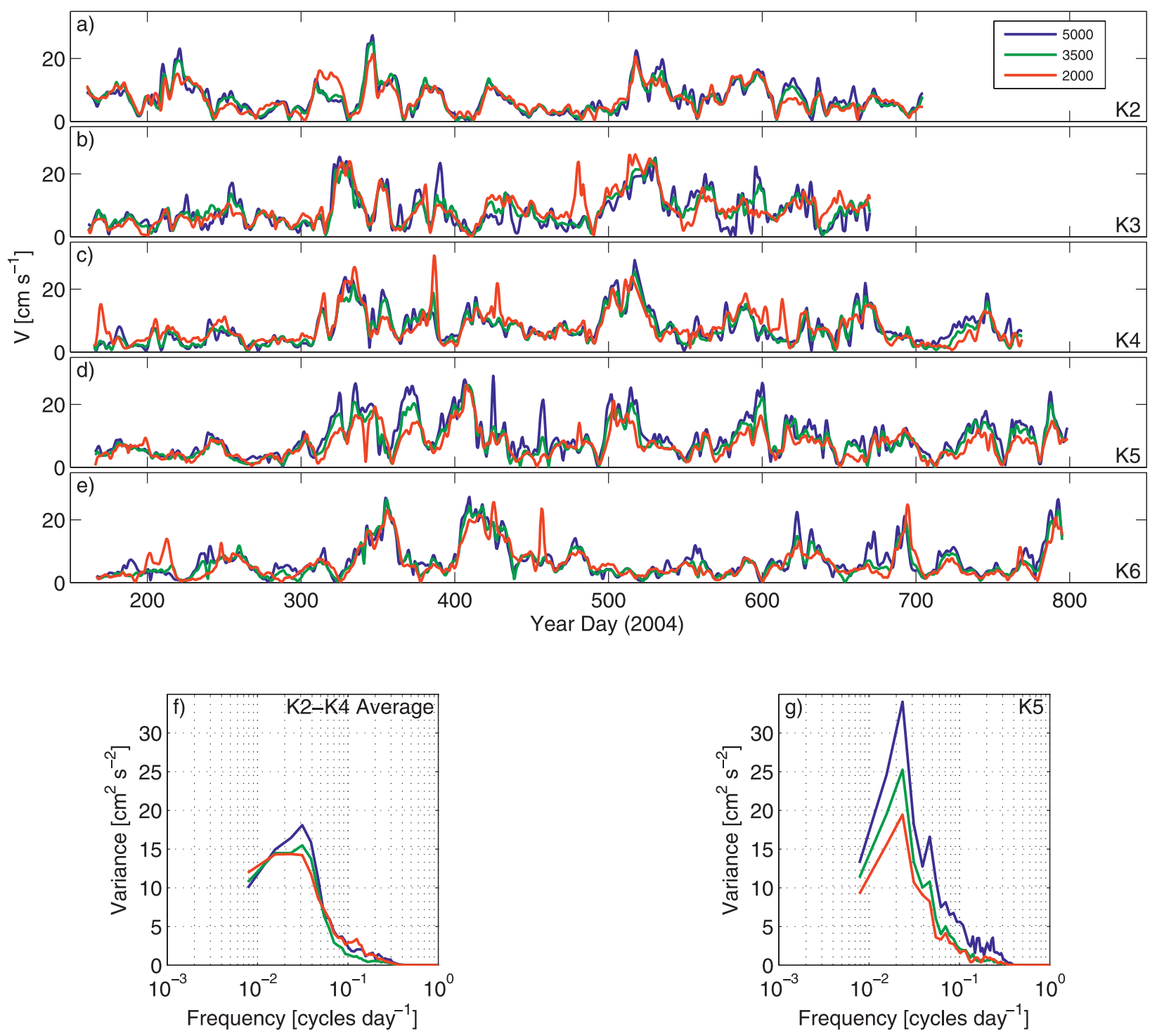

FIG. 2. (a)-(e) 72-h low-pass filtered current speed time series at 2000, 3500, and $5000 \mathrm{~m}$ for the moorings K2-K6. (f) Average variancepreserving kinetic energy power spectra over sites K2-K4 at 5000, 3500, and $2000 \mathrm{~m}$ using the Welch method of spectral estimation with a sample frequency Fs $=2$ cycles day ${ }^{-1}$, segment length of 128 days, Hanning window, and $50 \%$ overlap. (g) Power spectra; as in (f), but for mooring K5, which was located near a seamount.

$$
\gamma=\frac{1}{\cosh \left(H_{\mathrm{KESS}} / b\right)},
$$

where $H_{\mathrm{KESS}}=5300 \mathrm{~m}$, which was the reference depth used for the KESS CPIES analysis (Donohue et al. 2010). For comparison between $\eta^{\prime}$ and current measurements, $\gamma$ was calculated from $b$ for the current meter moorings using Eq. (3).

\section{Results}

The time series of $V$ are event-dominated (Figs. 2a-e) and kinetic energy spectra (Figs. $2 \mathrm{f}-\mathrm{e}$ ) show that energy is largely confined to the 30-60-day band. The ratios of current speed relative to $5000 \mathrm{~m}$ are plotted in Fig. 3d from the EOF method where the first-mode EOF accounted for more than $80 \%$ of the variance (Table 1). The fractional decrease in currents fits reasonably well within the framework of linear dynamics, and curves of $\cosh (z / b) / \cosh \left(z_{3} / b\right)$ for the best fit $b$ match closely to the observed fractional decrease in currents. A comparison of the best fit $b$ from the first-mode EOF and ratio methods give nearly identical results (Fig. 3e), with $r^{2}=0.997$ and unity slope within $95 \%$ confidence.

The estimated vertical trapping depths and associated length scales ranged from $5 \mathrm{~km}$ and $37 \mathrm{~km}$ at $\mathrm{K} 5$, which 

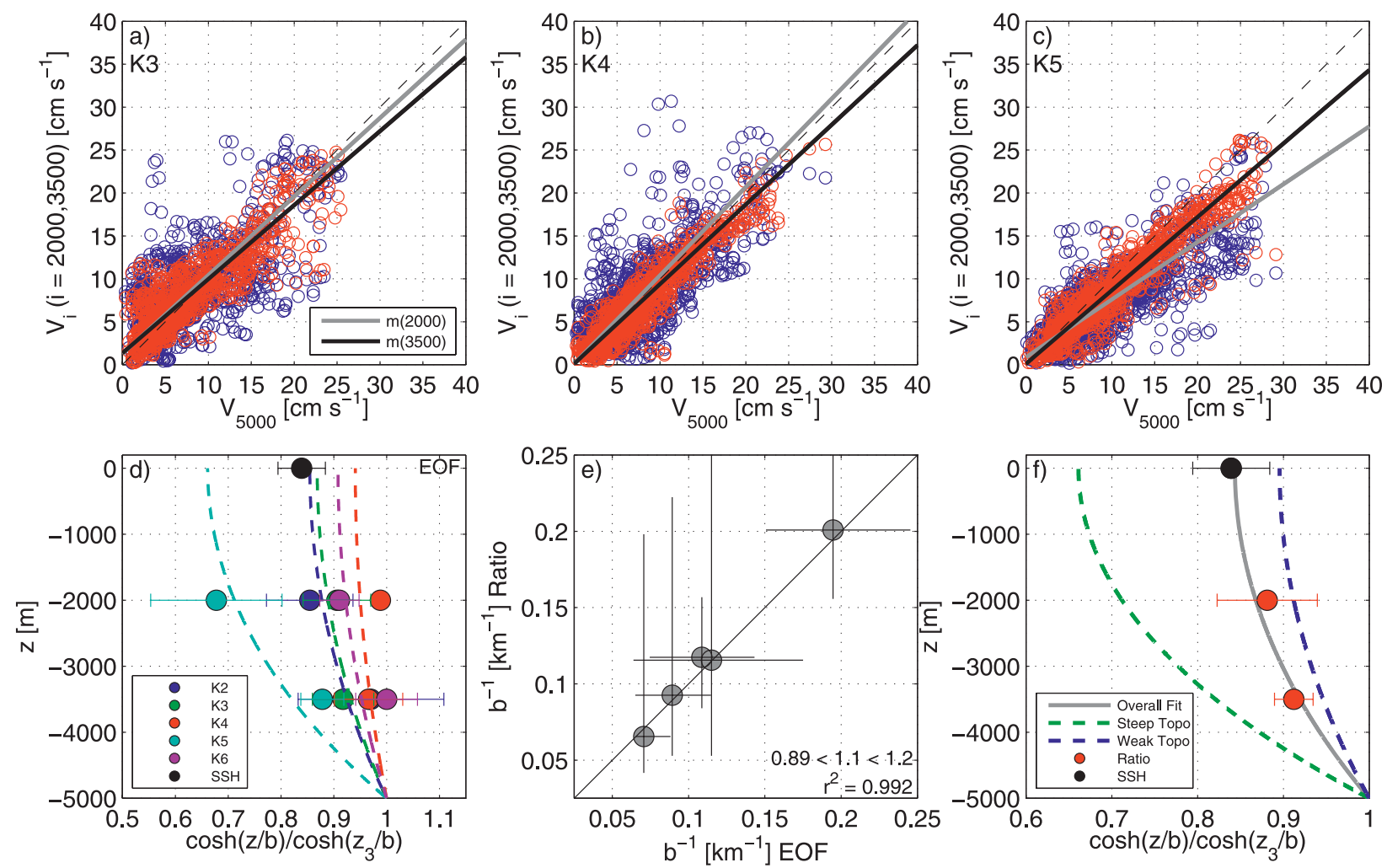

FIG. 3. (a)-(c) Scatterplots of $V_{2000}$ vs $V_{5000}$ (blue) and $V_{3500}$ vs $V_{5000}$ (red) with corresponding line fits for moorings K3-K5. The black line is the one-to-one line. (d) First-mode EOF amplitudes normalized by the EOF at $5000 \mathrm{~m}$. The black dot is the mean $\gamma$ for the 25 CPIES sites collocated on Jason-1 altimeter lines from J. Park (2011, personal communication) with error bars designating standard error of the mean. The dashed lines indicate $\cosh (z / b) / \cosh \left(z_{3} / b\right)$ for the best fit $b$ for each mooring location. (e) A comparison of the ratio and EOF methods, showing the inverse of the best fit $b$ for each site. Error bars were calculated from solving the system of equations in Eq. (1) from the bounds on the EOF and slope. (f) Overall mean fractional decrease in speed referenced to $5000 \mathrm{~m}$ with best fit (gray), best fit near steep topography [green; K5's fit as in (d)], and best fit in the absence of steep topography (blue; mean fractional decrease excluding K5). Error bars at 2000 and $3500 \mathrm{~m}$ are the standard error of the mean for the five current meter sites. Note that the $x$ axis scale has been expanded relative to $(\mathrm{d})$.

had a seamount located $\sim 35 \mathrm{~km}$ east of the mooring with a height $\sim 3500 \mathrm{~m}$ (peak at $2300 \mathrm{~m}$ vs $5800 \mathrm{~m}$ at K5) to $8-15 \mathrm{~km}$ and $60-110 \mathrm{~km}$, respectively, in the absence of steep topography (Table 1).

On average $\gamma$ for the current meter moorings from the best fit $b$ is $0.83 \pm 0.05$ (Fig. 3f). Near steep topography at $\mathrm{K} 5 \gamma$ is 0.63 , while the average along smoother topography with $\mathrm{K} 5$ removed is $0.88 \pm 0.02$ (Fig. 3f). The overall $\gamma$ average for the current meter moorings is consistent with results in J. Park (2011, personal communication), from SSH comparisons for 25 CPIES collocated along Jason-1 altimeter lines from

TABLE 1 . Vertical trapping depths $b$ and corresponding length scales $L=(N / f) b \approx 7 b$ for the ratio and EOF methods. Uncertainty ranges in values are in parentheses. An averaged buoyancy frequency of $N=0.6 \times 10^{-3} \mathrm{~s}^{-1}$, over 2000-5000 m, was used for these calculations.

\begin{tabular}{|c|c|c|c|c|c|}
\hline \multirow[b]{2}{*}{ Mooring } & \multicolumn{2}{|c|}{ Ratio } & \multicolumn{3}{|c|}{ EOF } \\
\hline & $b(\mathrm{~km})$ & $L(\mathrm{~km})$ & $b(\mathrm{~km})$ & $L(\mathrm{~km})$ & $\%$ Variance \\
\hline $\mathrm{K} 2$ & $8.65(3.91,18.91)$ & $60.1(27.2,131.3)$ & $8.69(5.71,15.66)$ & $60.4(39.7,108.8)$ & 96.3 \\
\hline $\mathrm{K} 3$ & $8.51(6.38,11.90)$ & $60.3(45.1,84.2)$ & $9.20(6.98,13.41)$ & $65.1(49.4,94.9)$ & 81.4 \\
\hline $\mathrm{K} 4$ & $15.28(5.05,24.03)$ & $109.6(36.2,172.4)$ & $14.16(11.34,15.34)$ & $101.5(81.3,110.0)$ & 94.1 \\
\hline K5 & $4.98(3.96,6.42)$ & $36.6(29.1,47.2)$ & $5.14(4.08,6.63)$ & $37.8(30.0,48.8)$ & 93.6 \\
\hline K6 & $10.80(4.50,18.91)$ & $81.0(33.7,141.9)$ & $11.20(8.72,15.35)$ & $84.0(65.4,115.2)$ & 81.0 \\
\hline $\mathrm{E}$ & $3.65(3.06,4.67)$ & $27.4(22.2,33.9)$ & $4.32(3.65,5.35)$ & $32.5(26.5,38.9)$ & 64.6 \\
\hline
\end{tabular}



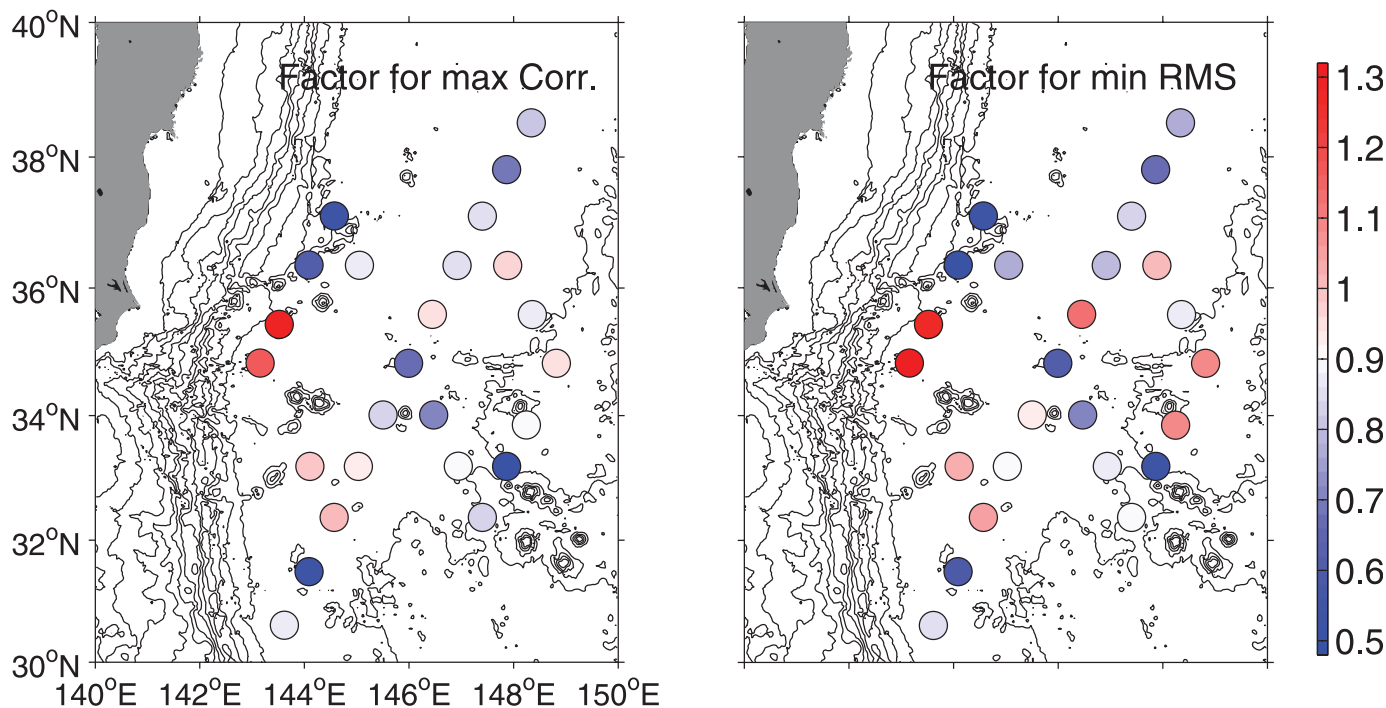

FIG. 4. Values of $\gamma$ calculated for CPIES SSH vs SSH from altimetry (left) for the maximum correlation and (right) for minimizing their rms differences. The two sites where $\gamma>1.2$ occur where the contribution of $\eta_{\text {ref }}$ is relatively small (less than $1 \%$ of $\eta_{\mathrm{bc}}$ ), so $\gamma$ has particularly wide error bars at these sites. Superimposed are bathymetry contours as in Fig. 1 with 1000-m contour intervals.

minimizing the rms difference between $\left(\eta_{\mathrm{alt}}^{\prime}\right)$ and $\left(\eta_{\text {cpies }}^{\prime}\right)(\gamma=0.84 \pm 0.05)$.

\section{Discussion and conclusions}

With the exception of mooring K5, observations from the five KESS moorings exhibit weak bottom trapping on the order of $O(8 \%)$ from 2000 to $5000 \mathrm{~m}$ (Fig. 3d). $\mathrm{K} 5$ exhibits more energy and trapping that is evident at all frequencies (Fig. $2 \mathrm{~g}$ ). The average spectrum from moorings K2-K4 (Fig. 2f), which were located on smoother topography, is less energetic, and trapping is only evident at periods longer than 20 days.

Even with the proximity of a seamount $\sim 35 \mathrm{~km}$ away, the topographic slope directly at K5 $(\alpha \approx 0.01)$ can only support TRWs of periods greater than $2 \pi / \alpha N=12$ days, the theoretical cutoff (Johns and Watts 1986), yet there is enhanced energy and trapping at periods less than 12 days (Fig. 2g). The average buoyancy frequency over the region from 2000 to $5000 \mathrm{~m}$ used in this calculation is $N=0.6 \times 10^{-3} \mathrm{~s}^{-1}$. It seems possible that for waves propagating around the seamount an evanescent solution may exist that would decay away from the seamount yet retain substantial amplitude at site K5.

There are at least three length scales of flow in this problem that can set the vertical trapping scale; the length scale of the topographically controlled eddies $\left(L_{E}\right)$, the internal deformation radius $\left(L_{D}\right)$, and the length scale of the topographic slope $\left(L_{T}\right)$ near steep topography $L_{E}>L_{D}>L_{T}$. It is hypothesized that smaller scales $\left[O\left(L_{T}\right)\right]$ are introduced to the flow at $\mathrm{K} 5$ from the nearby seamount through episodic advection of water parcels off the seamount by eddies impinging on the seamount. Greene et al. (2009) found that strong flow after a quiescent interval can advect water columns off isolated seamounts, resulting in cyclogenesis. The seamount under consideration in Greene et al. (2009) is the one east of K5. Their barotropic model revealed that submesoscale filaments develop during the cyclogenesis process on the order of the topographic Rhines' scale $\left[L_{R}=(U h / \alpha f)^{1 / 2}\right.$, where $U$ is the characteristic scale of the bottom horizontal currents] and wrap up into largerscale eddies. Because of the topographic influence and subinertial nature of these interactions, it is believed that these features would be bottom trapped. The $b$ and $L$ values at $\mathrm{K} 5$ in Table 1 support this conjectured mechanism, where $L=O(35 \mathrm{~km})$ and $L_{R}=O(35 \mathrm{~km})$ using $U=20 \mathrm{~cm} \mathrm{~s}^{-1}$ during the passage of an eddy (Fig. 2d), $h=5000 \mathrm{~m}, \alpha=0.01$, and $f=0.8 \times 10^{-4} \mathrm{~s}^{-1}$.

Further support for this hypothesis is that $\gamma$ values for the 25 CPIES collocated along Jason-1 altimeter lines have a spatial structure correlated with the local bathymetry (Fig. 4). The $\gamma$ values are lower in the southeast and northwest regions where there is steep topography, and K5 where a seamount exists. Small $\gamma$ values mean $b$ values are also small, exhibiting stronger bottom trapping over steeper slopes and less coupling to the surface layer.

A separate current meter mooring associated with KERE (Hallock and Teague 1996) during the 1990s also lends support to this explanation. KERE mooring $\mathrm{E}$ resided near $34.5^{\circ} \mathrm{N}, 144^{\circ} \mathrm{E}$ near a seamount $(\sim 40 \mathrm{~km}$ 

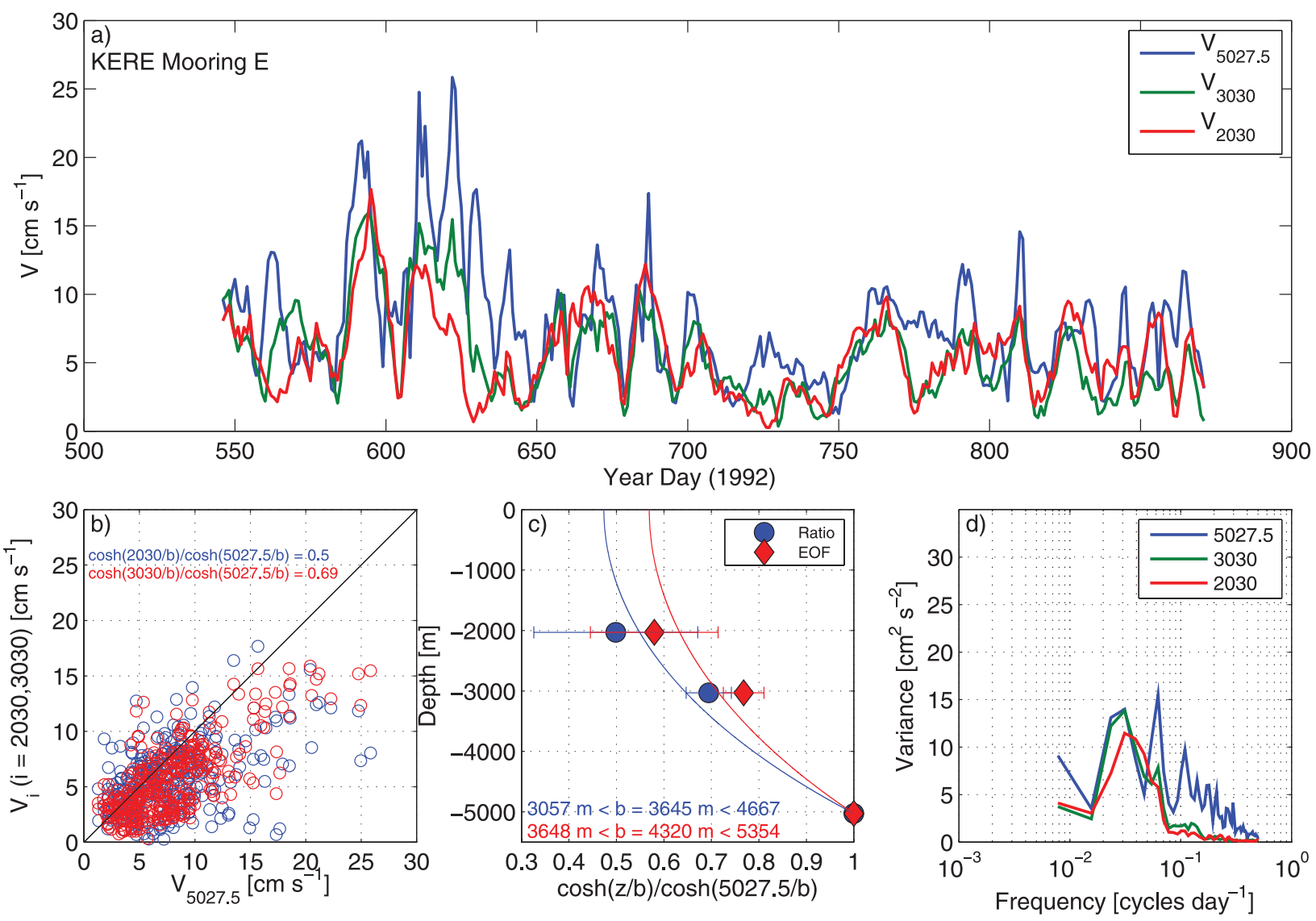

FIG. 5. (a) Current speed time series for 72-h low-pass filtered currents for the lower three current meters at KERE mooring E in year days referenced to 1 Jan 1992. (b) Scatterplot of current speeds at $2030\left(V_{2030}\right)$ and $3030 \mathrm{~m}\left(V_{3030}\right)$ vs at $5027.5\left(V_{5027.5}\right)$. (c) Fractional decrease in current speed by the ratio and EOF methods with estimates for the vertical trapping depth $b$. The error bars are the standard error of the mean for four 3-month segments. (d) Power spectra for KERE mooring E (as in Figs. 1f,g, except with Fs $=1$ cycle day ${ }^{-1}$ ).

to the southeast with height $3800 \mathrm{~m}$ ) (Fig. 1). The time series is episodic (Fig. 5a) with enhanced energy at periods less than 10 days (Fig. 5d) and trapping comparable to $\mathrm{K} 5$ with $b=O(4 \mathrm{~km})$ (Fig. 5c) where $\alpha<0.01$ at the mooring location. Given the nature of the KESS experimental design (spacing and avoidance of steep topography), it is beyond the scope of this work to test this hypothesis further.

Bottom intensified currents were observed from current meter moorings spanning the Kuroshio Extension jet and from CPIES SSH comparisons with altimetry as part of the KESS field program. In addition a current meter mooring in the KERE experiment exhibited bottom intensification. These measurements indicate that currents are weakly bottom trapped in the entire region with a vertical trapping scale $b=8.33 \mathrm{~km}$ (uncertainty range $7.1-10.3 \mathrm{~km}$ ). Currents were amplified and bottom trapping was more intensified in the vicinity of isolated seamounts. When the trapping function $\cosh (z / b)$ is fitted from surface to bottom the corresponding speeds and geostrophic pressure anomalies decrease on average to $83 \pm 5 \%$ at the surface from their values at the sea floor.

Acknowledgments. The authors thank the WHOI subsurface mooring group for successfully deploying and recovering the current meter moorings and the crews of the $R V$ Thompson, Revelle, and Melville. We wish to acknowledge Karen Tracey, Kathleen Donohue, and Andy Greene for their advice and careful processing of the CPIES data. This study was supported under the National Science Foundation Grant OCE0851246. JaeHun Park received additional support from KORDI Grants PE98561 and PE98563.

\section{REFERENCES}

Donohue, K. A., and Coauthors, 2008: Program studies the Kuroshio Extension. Eos, Trans. Amer. Geophys. Union, 89, 161, doi:10.1029/2008EO170002.

, D. R. Watts, K. L. Tracey, A. D. Greene, and M. Kennelly, 2010: Mapping circulation in the Kuroshio Extension with an 
array of current and pressure recording inverted echo sounders. J. Atmos. Oceanic Technol., 27, 507-527.

Fujio, S., and D. Yanagimoto, 2005: Deep current measurements at $38^{\circ} \mathrm{N}$ east of Japan. J. Geophys. Res., 110, C02010, doi:10.1029/ 2004JC002288.

Gill, A. E., 1982: Atmosphere-Ocean Dynamics. International Geophysics Series, Vol. 30, Academic Press, 662 pp.

Greene, A. D., 2010: Deep variability in the Kuroshio Extension. Ph.D. dissertation, University of Rhode Island, $176 \mathrm{pp}$.

—, G. G. Sutyrin, and D. R. Watts, 2009: Deep cyclogenesis by synoptic eddies interacting with a seamount. J. Mar. Res., 67, 305-322.

Hallock, Z. R., and W. J. Teague, 1996: Evidence for a North Pacific deep western boundary current. J. Geophys. Res., 101 (C3), 6617-6624.

Hamilton, P., 1990: Deep currents in the Gulf of Mexico. J. Phys. Oceanogr., 20, 1087-1104.

__, 2007: Deep-current variability near the Sigsbee Escarpment in the Gulf of Mexico. J. Phys. Oceanogr., 37, 708726.

Hogg, N. G., 1981: Topographic waves along $70^{\circ} \mathrm{W}$ on the Continental Rise. J. Mar. Res., 39, 627-649.

_ 2000: Low-frequency variability on the western flanks of the Grand Banks. J. Mar. Res., 58, 523-545.

- , and D. E. Frye, 2007: Performance of a new generation of acoustic current meters. J. Phys. Oceanogr., 37, 148-161.

Jayne, S. R., and Coauthors, 2009: The Kuroshio Extension and its recirculation gyres. Deep-Sea Res. I, 56, 2088-2099.
Johns, W. E., and D. R. Watts, 1986: Time scales and structure of topographic Rossby waves and meanders in the deep Gulf Stream. J. Mar. Res., 44, 267-290.

Lavelle, J. W., and C. Mohn, 2011: Motion, commotion, and biophysical connections at deep ocean seamounts. Oceanography, 23, 90-103.

Park, J.-H., D. R. Watts, K. L. Tracey, and D. A. Mitchell, 2005: A multi-index GEM technique and its application to the southwestern Japan/East Sea. J. Atmos. Oceanic Technol., 22, 1282-1293.

Rhines, P. B., 1970: Edge-, bottom-, and Rossby waves in a rotating stratified fluid. Geophys. Astrophys. Fluid Dyn., 1, 273-302.

Schmitz, W. J., P. P. Niiler, R. L. Bernstein, and W. R. Holland, 1982: Recent long-term moored instrument observations in the western North Pacific. J. Geophys. Res., 87, 9425-9440.

Smith, W. H. F., and D. T. Sandwell, 1997: Global seafloor topography from satellite altimetry and ship depth soundings. Science, 277, 1957-1962.

Thompson, R., and J. R. Luyten, 1976: Evidence for bottomtrapped topographic Rossby waves from single moorings. Deep-Sea Res., 23, 629-635.

Watts, D. R., C. Sun, and S. Rintoul, 2001: A two-dimensional gravest empirical mode determined from hydrographic observations in the subantartic front. J. Phys. Oceanogr., 31, 2186-2209.

Yanagimoto, D., M. Kawabe, and S. Fujio, 2010: Direct velocity measurements of deep circulation southwest of the Shatsky Rise in the western North Pacific. Deep-Sea Res. I, 57, 328337. 